\title{
The Methodology of Complex Continuous Training of the Students of Technical Universities to Innovative Activities
}

\author{
Izabella D. Belonovskaya \\ Aleksander E. Shukhman \\ Orenburg State University, Orenburg, Russia \\ Email: t251589@mail.ru \\ Marina A. Studyannikova \\ Orenburg branch of Volga state university of telecommunications and informatics, Orenburg, Russia \\ Natalia M. Minyaeva \\ Elena M. Ezerskaya \\ Orenburg State University, Orenburg, Russia \\ Olga F. Piralova \\ Omsk State Transport University, Omsk, Russia \\ Dilyara F. Barsukova \\ Kumertau branch of Orenburg State University, Kumertau, Russia
}

Doi:10.5901/mjss.2015.v6n2s3p36

\section{Abstract}

The urgency of preparing students for innovative activities is connected with the increasing requirements of the modern economy for the specialists' competencies. The paper presents a methodology for the integrated continuous training of the students of technical universities to innovative activity. The methodological basis of the study is backed with the systemic, competence-based and resource-based approaches. The methodology presents the system of competencies of innovation activities including five levels and four components at each level. The training is carried out within the three stages: the guidance stage, the formative stage and prospective stage. For every stage we have determined the objectives, mechanisms, approaches, teaching tools and planned results. The experimental testing of the methods has allowed to identify the main factors of successive teaching. The results of the study may be useful for researchers and practitioners studying the problems of innovative engineering education.

Keywords: methods; engineering education; innovation; innovative learning technologies.

\section{Introduction}

At present, the most important challenge to the development of innovative industries (such as information technology, aeronautics, innovative engineering, biotechnology) is a shortage of highly qualified personnel proficient in the methodology and technology of developing innovative products. The national educational and professional standards, the international recommendations include the requirements for the innovative competencies of the graduates. Training the students for innovation activities is a mandatory criterion for public and professional accreditation of the education programs in engineering and technology.

The Strategy of innovative development of the Russian Federation for the period up to 2020 sets the most important task of developing human resources in science, education, technology and innovation including the adaptation of the education system in order to develop the competencies, skills and behaviors from childhood that are necessary for 
an innovative society and knowledge-driven economy, as well as the formation of a system of continuous education.

The Strategy presents the core competencies of innovation that should be formed in the system of continuous education:

- the ability and willingness to lifelong learning, continuous improvement, retraining and self-training, occupational mobility, the aspiration for the new;

- the ability to think critically;

- the ability and willingness to a reasonable risk, creativity and entrepreneurial spirit, ability to work independently, willingness to work in a team and in a highly competitive environment;

- the foreign languages skills, which implies the ability to free everyday, business and professional communication.

Therefore, the development of the technique of formation of innovation competencies in continuing education is an urgent problem, which has been solved in our study. Under the innovation activity we mean a set of scientific, technological, organizational, financial and commercial activities, including the investments into new knowledge aimed at obtaining a technologically new or improved products or processes.

The problem of educating students for innovative activity has been widely discussed in the scientific and methodological literature.

Therefore, the article of Agranovish (Agranovich 2003) introduces the term "innovative engineering education" as the process and result of purposeful formation of specific knowledge, skills and methodological culture, as well as complex training in the field of engineering and technology for the innovative engineering activities through the appropriate content and methods training. It is proposed to use active learning innovative technologies such as contextual learning, problem-based learning, project-based approach and others.

The article (Temple, 2004) describes the experience of teaching innovation strategies in the educational programs of Glasgow Caledonian University (UK). The educational programs include training in all phases of the innovation process including the establishment of small businesses. When training the following principles have been applied: the principle of active learning (action learning), the principle of cyclic training (double loop learning), the principle of teaching basing on individual professional and real life experience of the students (experiential learning) and others.

A. Berglund's article (Berglund, 2012) examines the innovation from two sides - as a result of the students' training and as the technology in the course of their training. The innovative competencies become the most important result of studying in higher education and the programs that do not develop competencies are considered obsolete. The employers' surveys show that $95 \%$ of companies experience a shortage of engineering personnel because of the discrepancy of the level of training with modern requirements.

The modern recommendations for the modernization of engineering education are called CDIO (Conceive, Design, Implement, Operate) (Crawly, 2013). The innovations in CDIO embed in the learning environment as an integral part. The education program should provide for at least two opportunities: to gain experience of designing and implementation activities which develop the skills in designing the products, the processes and systems as well as the ability to apply knowledge in practice. The expertise can be achieved in terms of the graduation projects, apprenticeship and internship.

It also assumes the widespread use of the integrated education involving interdisciplinary complex tasks. It is desirable to attract employer representatives from the real enterprises of engineering and technology. In addition we recommend the use of practice-oriented methods of active learning when the students work in situations that simulate professional engineering activities such as design, simulation and case-study.

The article of Eyerer (Eyerer, 2003) discusses the features of the project-oriented approach in American universities. The project approach involves teaching centered on case studies. A case is a description of the actual situation from engineering practice. The students are required to analyze the case, to apply knowledge of engineering and technology, management and production organization and offer the most effective ways to solve the problem. The project technologies are particularly important for the teamwork. In this case, the team is offered the cases that fully imitate true engineering problems. Prototyping is widely used as a more simple process that is easier to manage within educational objects.

The article of Enmark (Enmark, 2005) presents several innovative technologies including contextual learning. Contextual learning involves the study of theoretical knowledge in relation to their specific application in the future professional activity. Contextual learning increases students' motivation, results in deep knowledge.

The teaching technology based on experience is widely represented in the study of Kolb (Kolb, 2001). All the students' activities can be classified according to the degree of abstraction varying from a concept to a certain experience and according to the degree of activity that varies from simple observation and passive study to an active experiment.

It is necessary to manage the teaching process with specific actions, to deduce the generalities and abstraction on 
the students' own experience.

The article of Muratov (Muratov, 2008) examines the use of competence-based approach while designing the teaching programs for the students' innovation activity in the field of engineering and technology. The authors have justified the need to introduce a competencies related to the field of innovation.

On the assumption of the submitted competencies we have submitted the teaching content in the field of innovation including a core which is invariant to all areas and levels of training, providing the students with universal and professional competencies that are common for all levels of technical (technological) education programs, and the variable part reflecting the particular implementation of the innovative projects in a particular subject area.

A comprehensive system of training for a bachelor degree for innovation is presented in the study of Naumkin (Naumkin, 2008). The author suggests to develop the ability for innovative engineering in the course of teaching technical disciplines. It is necessary to integrate the fundamental science and applied engineering disciplines and extracurricular students' work in academic competition and research environment.

The approach to training the graduate students for innovation is presented in Butler's study (Butler, 2006). The authors have developed a model of training for a master's degree in engineering and technology to provide innovation and specified the didactic conditions for its implementation. The analysis of the master's core activities has shown a close relationship between innovative and research activities.

\section{Methodological Framework}

\subsection{The system approach}

In our research the system approach has become foundational. The specificity of the system approach is to consider the process of research competencies formation in terms of the integrated system of its components, in the variety of their connections and relationships that are in constant development. It contributes to the identification of the integrated system properties and quality characteristics that are missing in the system components.

\subsection{The competence-based approach}

The second important methodological approach is the competence-based approach centered around the concepts of competence and competency. For our research the competence-based approach determines the competencies as the key component of the education content model. A competence as a complex object consists of the content-related components: knowledge, skills, values, experience. In the structure of the competence we have identified the contentrelated levels determining the degree of autonomy, responsibility, creativity of the related activities. Using a complex structure allows to determine the student's level of competence.

\subsection{The resource-based approach}

While arranging the students' training for innovation the educators should also consider the possibility of practical implementation of the submitted approaches. To achieve this the resource-based approach seems the most useful. Applying the resource-based approach in designing the model of students' training for innovation activity involves the assessment of the organizational and resource supply of the proposed technologies for implementation.

\subsection{The principles of training the students for innovative activity}

The effective training of the students for innovative activity can be carried out only under some methodological principles: interdisciplinarity, continuity, professional orientation, the subject's activity, integrity. We have studied every principle:

1. The principle of interdisciplinarity requires the introduction of innovative technologies of active learning in all general education, general technical and professional disciplines. The innovation activity requires a deep knowledge of economics, legal and social aspects of innovation implementation, so it is necessary to use complex projects and assignments including both the technical components and marketing, organizational, legal ones.

2. The principle of continuity requires the arrangement of training for innovation at all levels while ensuring the continuity of educational content and continuous expansion of the specialist's scope of innovation raising his awareness in the field of innovation. 
3. The principle of professional-orientation supposes training for innovation that can only be achieved with a constant focus of training on the future professional activity. The innovative training should not be detached from real engineering problems, it is necessary for the students to know the specifics of innovation in their professional field.

4. The principle of subject's activity. Achieving the mastery of innovation activities is only possible with the use of innovative forms of active learning like the problem-based, project-based learning, learning from experience. In addition, the student should take the advantage of the university innovative environment, its infrastructure, innovative events: seminars, conferences, contests and competitions.

5. The principle of integrity. The national and international experience in training students for innovation shows that the significant results can be achieved by combining the material, personnel, financial resources of the educational organization and the employers as the representatives of industry innovation. The interaction of education and industry can be performed in a number of areas. It may include excursions, practices and internships, the experts from industry participating in designing the syllabus of the educational process, its implementation, assessing the training efficiency, using real industrial problems and projects.

\section{Results}

\subsection{The content of the model of training students for innovation}

The developed model of teaching students for innovative activity consists of the following interrelated components: the target, structural, procedural, technological, effective, evaluative.

\subsubsection{The target component of the model}

The target component of the model includes the hierarchy of the educational objectives the most important of which is to train the students for effective innovation activity in today's innovation economy. There are also secondary objectives related: the study of the theoretical foundations of innovation, technological, economic, legal aspects of the innovation process; the experience in implementing the innovative projects, teamwork, management and division of responsibilities; development of the research skills, creative abilities and creative thinking; increasing the students' motivation to train for their future profession in the field of innovative industries.

\subsubsection{The structural component of the model}

The structural unit of the model is a description of the major structural components of the innovation competencies developed during the course:

1. The pragmatist component includes a set of professional skills.

2. The cognitive component of the competence supposes a body of knowledge.

3. The axiological component is presented with a system of values, attitudes, rules and principles of behavior in professional community and professional activities.

4. The empirical component describes the specialist's experience.

\subsubsection{The procedural component of the model}

The procedural component determines the main stages of training.

A guidance stage aims to develop professional knowledge, skills, initial experience and axiological attitudes in the field of innovation providing the students with the orientation of innovation.

The result: formation of the general scheme and orientation foundations of innovation, accumulation of the guiding methods of innovation activity, the emergence of structural and content-related components of the innovation competence components - the cognitive, operational, empirical and axiological.

The formative stage: the development of preformed professional knowledge, skills, experience and axiological relations in the field of innovation providing initial willingness to innovate. The result: the knowledge about the innovative methods of operation, the ability to perform innovation, receiving the initial experience in innovation, as well as formation of axiological attitude to innovation, to the need of innovative transformation.

The prospective stage: formation of innovation competencies as the integration of structural and content-related 
components - the cognitive, operational, empirical and axiological.

\subsubsection{The technological component of the model}

The technological component presents active innovative technologies and means of teaching applied at each stage of teaching.

These technologies and tools include special courses, professionally oriented thematic meetings, seminars, disputes, excursions at the guidance stage of the training; professionally focused tasks and project assignments, innovative engineering games at the formative stage of the training, innovative problem situations, case studies, projects, innovative apprenticeship at the prospective stage of education.

The problematic manufacturing situation represents a single, integrated, relatively consistent set of circumstances conditioned by a certain working situation to be solved by means of innovation.

The cases of innovative production content represent the structured (or semistructured) description of the existing crisis situation that has resulted in some difficulties for further production development.

The innovative engineering game is a kind of integrative quasi-professional activities aimed at the development of perception and acquisition of the innovative engineering reality by the students through the simulation game recreating the roles of the main behavior types of the engineers within certain game-driven models of the engineer professional work.

The innovative engineering tasks implemented in the educational university process represent a didactic model of the problematic engineering situation related to its main types - the design-and-engineering, managerial, research, experimental that contains the data and conditions necessary and sufficient to resolve it with available knowledge and experience in order to develop the engineering competence of the future professionals of the field.

The apprenticeship at manufacture as a part of the process of vocational education of the technical college student has the greatest potential to create conditions for the formation of innovation competencies.

\subsection{The efficiency component}

The efficient component describes the educational result in the form of the following levels of competencies identified in our previous publications (Belonovskaya, 2012; Shukhman, 2013):

1- readiness to practical action according to a typical sample.

2- readiness for self-regulated responsible actions.

3- readiness for the applied independent practice in innovative environments.

4- readiness for the design, construction, implementation and realization of the innovative products, technologies and services.

5- willingness to research and forecast in the field of innovation.

The content of the competencies has been developed on the basis of the TUNING project recommendations centered on the professional standards offered by the employers for a variety of engineering and technology fields.

\subsubsection{The evaluation component}

The evaluation criteria includes the criteria for assessing the effectiveness of the system of training the students for innovation:

1. A motif-based criterion - the criterion reflects the direction, goals and objectives of training students for innovation.

2. A system-procedural criterion - the criterion that assesses the dynamics and quality of the process of educating the students to innovate.

3. An effectiveness criterion - the criteria that characterizes the level of achieving the planned level of targeted training of the students for innovation.

4. A resource criterion - the criterion that characterizes the availability of the necessary material, human and other resources to effectively teach students for innovation.

5. The innovative criterion - the criterion characterizing the degree of novelty and innovative tools, methods and techniques of training used in students' training for innovation. 


\section{Discussions}

The individual elements of the developed model: the competencies framework, the system of criteria, the system of innovative technologies and learning tools have been tested in relation to the bachelor's and master's degree in "Engineering", "Information and Computing Equipment","Aircraft","Power and Electrical Engineering" in the Orenburg State University. The analysis of the experience of implementation of this education has allowed to identify the major successful factors for the formation of innovation competencies.

1. The factor of the long-term goals is characterized by the fact that the determination of the long-term prospects on the basis of existing competitive advantages and innovative capacity creates opportunities for planning the future, more responsible and qualitative training in specific priority areas, focusing on sunrise areas of knowledge and rapidly developing areas of activity, differentiation of the strategy of innovative development.

2. The factor of continuity of the formative processes in modern higher education is that the education standards have a successive character, in this regard the graduates from various levels and stages of education will be able to continue expanding the existing educational and innovation competencies at the next level or stage.

3. The factor of university focus on high achievement helps to attract talented young people into higher schools, to retain the talented members of the academic staff, to attain the university image perfection and increase its ranking.

4. The factor of integration of the university and enterprise resources provides the students and the university with transition from a scarce number of disciplines and highly-specialized qualifications as the knowledge formally confirmed by a diploma to a set of core competencies and ability and willingness to perform certain innovative activities that are significantly demanded in the workplace. The integration of the scientific, financial and material resources of the university and the company provides the development and implementation of multidisciplinary suprasectoral computer technologies to create significant and unique scientific and educational practical groundwork through the systematic capitalization and repeated use of transdisciplinary new knowledge in practice, to establish rational, efficient schemes and algorithms of the engineering (polytechnic) transfer system, which is essential for to develop the innovative competence.

5. The factor of intensification of education is related both to the introduction into the teaching process the technology of careful management and selection of the most productive and effective teaching technologies. The integrated informatization of education, the introduction of smart technologies create a new educational environment in which teaching changes its characteristics and provides the students with a wider range of innovative competencies in a shorter time. These technologies of intensive training include, in particular, the development of a system of regular participation of the students and staff in joint processing of the real projects (within the framework of virtual project-oriented teams) on request on the basis of the advanced acquiring and applying the key competencies and the technologies of computer engineering.

6. The factor of actualizing the students' resources describes the opportunities for students to acquire the innovative competence. All the technologies and means of competencies formation including the tasks, assignments, games, case studies, problem situations, work practice, primarily interact with the previous experience of the learner and rely on it and then create new opportunities for its actualization.

\section{Conclusion}

The developed technique of the integrated continuous training of the students in engineering to innovate appeared promising in the course of experimental testing. The key features of our approach is the continuity of training at all levels of higher education, integrative learning tools and technologies. The training is carried out in three stages : the guidance stage, the formative stage and the perspective stage. For each stage the objectives, mechanisms, approaches, learning tools and deliverables have been determined. The experimental testing of the methods has allowed to identify the main factors for successful training.

\section{References}

Belonovskaya, I., Shukhman, A., (2012) Continuous educational programs constructing for training specialists in innovative branches of economy on the basis of generalized competences system Proceedings of the International Conference on Interactive Collaborative Learning (ICL 2012), DOI: 10.1109 / ICL.2012.6402100

Berglund A. (2012) Do we facilitate an innovative learning environment? Student efficacy in two engineering design projects. Global 
Journal of Engineering Education (vol.14 (1), pp.26-31).

Crawley, EF, Edström, K., \& Stanko, T. (2013) Educating engineers for research-based innovation - Creating the learning outcomes framework. Proceedings of the 9th International CDIO Conference, Cambridge Massachusetts.

Enemark, S. (2005) Innovation in surveying education. Global J. of Eng. Educ. (Vol. 6, pp.153-159).

Eyerer, P., Hefer, B. \& Krause, B. (2003) The reformation of technical education through project-orientation education (TheoPrax). Global J. of Eng. Educ. (Vol. 4, pp.281-286).

Kolb, DA, Boyatzis, RE, \& Mainemelis, C. (2001) Experiential learning theory: Previous research and new directions. Perspectives on thinking, learning, and cognitive style: The educational psychology series Mahwah, NJ, Erlbaum. (pp. 227-247).

Shukhman, A., Belonovskaya, I., Motyleva M. (2013) Individual learning path modeling on the basis of generalized competencies system Proceedings of the 2013 IEEE Global Engineering Education Conference (EDUCON) (pp. 1023-1026) DOI: 10.1109 / EduCon.2013.6530233

Agranovich, B.L.. Chuchalin, A.I., Solov'ev, M.A. (2003) The innovative engineering education. Inzhenernoe obrazovanije. (N 1, pp. 1114.)

Dvoretskiy, S.I., Muratova, E.I., Osina, S.V. (2006) The development and implementation of the model of training for a Master s degree in engineering and technology for innovation. Nauka i obrazovanije. Inzhenernoe obrazovanije. (N 10) URL: http://technomag. edu.ru/issue/42077.html

Muratova, E I., Fedorov, I.V. (2009) The competence-based approach to designing programs of higher professional education for training in the field of engineering and technology to innovate. Inzhenernoe obrazovanije (N 5, pp. 48-59).

Naumkin, N.I. (2008) The methodical system of forming the abilities to innovative engineering among the students of technical universities. Saransk: Izd. Mordovskogo Univ. 172 p.

Temple B.K., Cheremisina I.A, Smith A. (2004) Flexible learning technologies in the innovative university. Inzhenernoe obrazovanije. (N 4, pp. 80-87.). 